\title{
LIVRO DIDÁTICO DE LÍNGUA PORTUGUESA: NOVO CENÁRIO, VELHOS PROBLEMAS
}

\author{
Lilian Cristina Buzato RITTER \\ (Universidade Estadual de Maringá) \\ bliliancristina@hotmail.com \\ Claudia Valéria DONÁ HILA \\ (Universidade Estadual de Maringá) \\ claudia2012@hotmail.com \\ Edna Mariucio ARANHA \\ (Universidade Estadual de Maringá) \\ aranha74@hotmail.com
}

\begin{abstract}
Resumo. Este artigo apresenta a análise de uma unidade didática presente em um livro didático (LD) adotado por escolas da rede pública paranaense para o ensino fundamental, resultado do trabalho da disciplina "Texto e ensino", ministrada no PROFLETRAS. O objetivo é observar se a perspectiva teórica dialógica e enunciativa, no que concerne aos gêneros do discurso, é adotada pelos autores, a partir das propostas de leitura e escrita apresentadas com o gênero crônica. A nossa fundamentação teórica apoia-se na Análise Dialógica do Discurso (BAKHTIN, 2003), tendo como princípio a definição de texto como enunciado concreto e as relações dialógicas que atravessam o discurso. Os resultados evidenciaram que os autores do LD analisado, em relação à prática da leitura, por não contemplarem as condições de produção e as relações dialógicas que engendram a produção de sentidos de todo e qualquer enunciado, provocam no aluno-leitor uma visão naturalizada e pouco crítica do modo de funcionamento do gênero. Já, em relação à proposta de produção textual, não encontramos subsídios teóricos em relação ao estudo da crônica, no que concerne aos seus aspectos temáticos, composicionais e marcas de estilo, o que resultou em uma proposta muito mais voltada a aspectos relacionados à tipologia textual que propriamente ao gênero do discurso.
\end{abstract}

Palavras-chave: Livro Didático. Gênero do Discurso. Análise Dialógica do Discurso.

\section{PORTUGUESE LANGUAGE TEACHING AND TEXTBOOKS: NEW SCENARIO, OLD PROBLEMS}

Abstract. This article presents the analysis of one teaching unit in a textbook (TB) adopted by public elementary schools in Paraná. This study is the outcome of some reflections generated in the subject "Text and education ", which is part of the Mestrado Profissional em Letras (PROFLETRAS). The study main goal is to identify the theoretical perspective adopted by the authors, regarding the notion of speech genres upon which the reading and writing activities on chronicles were developed.

Pensares em Revista, São Gonçalo-RJ, n. 7, pág. 111-126, jul. / dez. 2015

DOI: $10.12957 /$ pr.2015.18406 
Our theoretical framework draws on Dialogic Discourse Analysis (BAKHTIN, 2003) that defines the text as set of concrete and dialogical relations involved in speech. As far as reading is concerned, and since the authors of the TB do not consider the conditions of production and the dialogic relations that engender the production of meaning, the results of the study showed that the student-readers take an uncritical and naturalized view on how a certain genre functions. In respect to text production, we did not find a clear theoretical framework regarding the study of chronicle, with respect to its thematic and compositional aspects, and to its style. Therefore, the TB presents an approach to the teaching of Portuguese that focuses on text type rather than on genre.

Keywords: Textbook. Genre. Dialogic Discourse Analysis .

\section{Introdução}

O presente artigo origina-se de trabalho apresentado na disciplina de "Gêneros Discursivos/Textuais e Ensino" do Mestrado Profissional em Letras PROFLETRAS (UEM / UFRN). Trata-se da análise de uma unidade didática do livro didático "Português Linguagens" de William Roberto Cereja e Thereza Cochar Magalhães, da editora Saraiva, do oitavo ano, adotado por escolas da rede estadual paranaense, a partir do ano letivo de 2014. O objetivo da análise é observar em que medida a perspectiva teórico-metodológica adotada pelos autores se efetivou nas propostas de leitura e escrita sugeridas no livro didático (doravante LD). Desde já, vale pontuar que os autores assumem os gêneros do discurso como objeto de ensino, fundamentando-se nos pressupostos teóricos de Bakhtin (2003).

Sabemos que o LD é o principal material de apoio utilizado para a aplicação das aulas nas escolas públicas. Assim, justifica-se a necessidade de avaliarmos as coleções didáticas, que estão aparentemente em consonância com as propostas dos Parâmetros Curriculares Nacionais-Língua Portuguesa [PCN-LP] (1998) e das Diretrizes Curriculares Estaduais do Paraná [DCE] (2008), as quais defendem uma abordagem para o ensino de língua fundamentada na concepção sociointeracionista da linguagem, preconizada pelas reflexões do Círculo de Bakhtin. De acordo com esta concepção, a linguagem é uma forma de interação social, os sujeitos falantes não são passivos, mas históricos e ideologicamente situados e se constituem na interação com o outro. 
É salutar a reiteração dos PCN-LP (BRASIL, 1998) quanto à função social do ensino de Língua Portuguesa, ao confirmarem que: "Nessa perspectiva, língua é um sistema de signos específico, histórico e social, que possibilita a homens e mulheres significar o mundo e a sociedade" (BRASIL, 1998, p.20). Enfatizam ainda que a interação pela linguagem decorre da necessidade de um querer dizer algo para o outro, num determinado tempo histórico conforme circunstâncias interlocutivas. As DCE (PARANÁ, 2008) apontam para a mesma direção, destacando que: "[...] se considerem os aspectos sociais e históricos em que o sujeito está inserido, bem como o contexto de produção do enunciado, uma vez que os seus significados são sociais e historicamente construídos" (PARANÁ, 2008, p.49).

O processo de construção de um enunciado concreto se dá no rol de outros enunciados, determinados por suas esferas de comunicação. Nesse processo também existe um movimento dialógico entre os interlocutores, porque ambos requerem recepção/compreensão responsiva ativa dos enunciados. Nessa perspectiva, com o objetivo de se evitar o caos comunicativo, a sociedade se utiliza do que Bakhtin (2003, p. 261-262) denominou gêneros do discurso. No interior de cada atividade de interação verbal que desenvolvemos, agimos e interagimos por meio de enunciados concretos moldados na configuração sócio-histórica dos gêneros discursivos.

Em contextos de ensino, como leitores/produtores de textos, os alunos estão imersos em práticas sociais e em atividades de linguagem letradas, pertencentes a diferentes situações comunicativas. Para agirem e interagirem nessas situações, é preciso saber empregar adequadamente os gêneros discursivos, de acordo com os pressupostos bakhtinianos.

Nessa direção, elegemos como objetivo desse artigo discutir o tratamento dado ao gênero do discurso em um livro didático, a partir das atividades didáticas propostas para as práticas da leitura e escrita. $\mathrm{O}$ trabalho apoia-se teoricamente nos estudos bakhtinianos (BAKHTIN, 2003) e de seus seguidores, tendo como princípio a definição de texto como enunciado concreto e as relações dialógicas que atravessam o discurso.

O artigo configura-se em três partes, além desta introdução, a saber: primeiramente, retomamos brevemente os conceitos bakhtinianos de enunciado concreto e dialogismo; na sequência, apresentamos nossas 
considerações a respeito da elaboração didática proposta na seção de leitura e de produção textual, para, em seguida, finalizarmos o trabalho.

\title{
1. Os gêneros do discurso: considerações sobre o enunciado concreto e o dialogismo
}

Segundo Rodrigues (2007, p.2012), a noção de gêneros do discurso surge na década de 90 na disciplina de Língua Portuguesa. A estudiosa explica que não basta tomar o texto como unidade de ensino, se não se adota uma concepção de texto como "meio" de interação, isto é, o texto na sua condição de enunciado, considerando-se as condições sociais de interação. Ensinar língua materna em consonância com este preceito exige uma nova postura do professor que deve trabalhar com a língua em situação de uso, levando em conta seus aspectos históricos, sociais e ideológicos. Assim, não se concebe mais um ensino de língua voltado para a palavra isolada do seu contexto, uma vez que a palavra só tem significado em correlação com o outro.

\begin{abstract}
A compreensão de uma fala viva, de um enunciado vivo é sempre acompanhada de uma atitude responsiva ativa (conquanto o grau dessa atividade seja muito variável); toda compreensão é prenhe de resposta e, de uma forma ou de outra, forçosamente a produz: o ouvinte torna-se o locutor. A compreensão passiva das significações do discurso ouvido é apenas o elemento abstrato de um fato real que é o todo constituído pela compreensão responsiva ativa e que se materializa no ato real da resposta fônica subsequente (BAKHTIN, 2003, p.291).
\end{abstract}

Logo, é importante atentar para o conceito de enunciado como unidade real da comunicação verbal, conforme defende Bakhtin (2003, p.294), "A fala só existe, na realidade, na forma concreta dos enunciados de um indivíduo: do sujeito de um discurso-fala. O discurso se molda sempre à forma do enunciado que pertence a um sujeito falante e não pode existir fora dessa forma".

O filósofo russo afirma ainda que falamos por meio de enunciados, determinados pelo contexto e por interlocutores. Não falamos por meio de orações ou palavras isoladas, pois, segundo o autor, [...] "As pessoas não trocam orações, assim como não trocam palavras (numa acepção rigorosamente linguística), ou combinações de palavras, trocam enunciados constituídos com a ajuda de unidades da língua [...]" (BAKHTIN, 2003, p.298). Desse modo, observamos que o conceito de enunciado considera a língua no processo de interação entre sujeitos com projetos discursivos pautados em 
valores culturais, sociais e ideológicos, inseridos num determinado contexto histórico.

Portanto, se tomamos a língua como essencialmente dialógica, devemos entendê-la não somente como sistema, mas como pertencente ao campo do discurso e se estabelecendo na comunicação verbal concreta. Nesta perspectiva, o conceito de dialogismo, segundo Costa-Hübes (2014, p.16), "é o princípio básico que sustenta os estudos do Círculo de Bakhtin". Conforme este conceito, a língua em sua concretude é dialógica, conferindo à presença do interlocutor um fato imprescindível para o estabelecimento das relações dialógicas que definem o sujeito como ser social. O outro sempre será a medida, a diretriz que o sujeito levará em conta para a sua tomada de decisões e, por conseguinte, para a criação do seu próprio discurso. Nas palavras do autor:

De fato, o ouvinte que recebe e compreende a significação (linguística) de um discurso adota simultaneamente, para com este discurso, uma atitude responsiva ativa: ele concorda ou discorda (total ou parcialmente), completa, adapta, apronta-se para executar, etc., e esta atitude do ouvinte está em elaboração constante durante todo o processo de audição e de compreensão desde o início do discurso, às vezes já nas primeiras palavras emitidas pelo locutor (BAKHTIN, 2003, p. 291, grifos do autor).

O conceito bakhtiniano de dialogismo destaca a posição do interlocutor nas situações de interação verbal. Estas relações dialógicas não envolvem apenas o diálogo face a face, mas diversas possibilidades de enunciados. Nestes há um autor que concretiza sua voz, a qual pode sofrer uma réplica, via outro gênero discursivo. Essa atitude responsiva ativa pode ocorrer com gêneros anteriores ou posteriores da cadeia de comunicação verbal.

Nesse sentido, Costa-Hübes (2014, p.17) afirma que as relações dialógicas ultrapassam estudos restritos aos elementos do sistema da língua, os quais não consideram o contexto e os interlocutores, "[...] estendendo-se para o discurso, para o extralinguístico, ou seja, para o extraverbal, compreendido como a dimensão e o caráter social do enunciado." Assim, quando falamos ou escrevemos, sempre devemos pensar o interlocutor como o 'outro' caracterizado por uma posição social e que determina as escolhas linguísticas e composicionais determinantes do gênero discursivo que o locutor escolherá para efetivar a interação. Portanto, há um vínculo indissolúvel entre o enunciado e a situação social, ou seja, existe um horizonte extraverbal que é 
constitutivo do enunciado. A ausência de ligação com o contexto pode comprometer a compreensão do enunciado pelos interlocutores.

Feitas estas considerações, nas próximas seções discutimos em que medida as atividades de leitura e escrita sugeridas no LD analisado trabalham a língua a partir da abordagem enunciativa aqui estudada, permitindo que 0 nosso aluno seja de fato um interlocutor ativo em relação aos encaminhamentos didático-metodológicos apresentados pelos autores.

\section{Atividades de leitura e escrita no LD}

Cereja e Magalhães (2012, p.4), conforme teorizam no Manual do Professor (MP), alegam que o ensino de português, na atualidade, deve abordar a leitura, a produção de texto e os estudos gramaticais de uma mesma perspectiva da língua - a perspectiva da língua como instrumento de comunicação, de ação e de interação social. Assim, os autores explicitam que o enfoque, a metodologia e as estratégias de ensino de língua portuguesa são alterados a partir de uma mesma perspectiva textual e enunciativa.

Os autores do LD fundamentam-se nos postulados teóricos de Bakhtin (1997) e de Schneuwly e Dolz (2004) para explicar que o trabalho com os gêneros como o objeto de estudo exige que se proceda à seleção daqueles que mais interessam aos objetivos da escola. Afirmam ainda, que se deve pensar na elaboração de uma progressão curricular levando em conta a necessidade de se trabalhar em espiral, em todas as séries escolares a partir de gêneros de grupos diferentes, conforme entendem os pesquisadores de Genebra.

Tendo estas informações como parâmetro, procedemos à análise de um capítulo da Unidade 2, do livro do oitavo ano, intitulada - Adolescer. Esta unidade está subdividida em três capítulos, sendo o primeiro: Adolescência: a porta da vida?- em que Cereja e Magalhães (2012) propõem o estudo do gênero discursivo crônica.

A Unidade 2 inicia com o poema Necessidades de Elias José. Os autores do LD sugerem que seja realizada a leitura e que o professor faça perguntas para estimular os alunos a relacionarem o tema da unidade com o tema abordado pelo poeta. Como outras opções didáticas propõem: 
a) Começar o bimestre assistindo a um dos vídeos propostos na seção Fique ligado! Pesquise! e debater com os alunos o papel do adolescente na história.

b) Ouvir e debater com os alunos o conteúdo da canção "Pais e filhos".

c) Pedir aos alunos que respondam em recortes de papel colorido à pergunta - $\mathrm{O}$ que é adolescência? - e depois leiam as respostas. Em seguida, afixar os recortes no mural da classe.

d) Assistir um dos vídeos sugeridos em Fique ligado! Pesquise! e debater o tema do filme e sua relação com o que será visto na unidade ou os valores humanos que o filme coloca em discussão.

Cereja e Magalhães, p.157, 2012.

Consideramos interessantes as atividades apresentadas como motivação ou pré-leitura para a abertura da unidade, pois a variedade de sugestões permite que o professor, conforme a sua realidade, possa selecionar a que melhor se adeque ao contexto de sua sala de aula. Como as atividades são variadas e apresentadas em suportes distintos, permitem também que o professor possa discutir inicialmente com os alunos acerca da diversidade discursiva e de suas condições de produção/recepção.

Assim, ainda que o objetivo destas atividades seja preparar o aluno para a temática da unidade, nada impede que o professor, como mediador do conhecimento, faça as intervenções necessárias, acrescentando, suprimindo, enfim, readequando as atividades propostas no LD, a fim de possibilitar um tratamento dado ao gênero na perspectiva interacionista da linguagem, levando em conta o aluno como interlocutor.

O capítulo que abre a unidade é intitulado "Adolescência: a porta da vida?" e organiza-se da seguinte forma:

\begin{tabular}{|l|l|}
\hline Estudo do texto & $\begin{array}{l}\text { Compreensão e interpretação; A linguagem do texto; } \\
\text { Leitura Expressiva do texto. }\end{array}$ \\
\hline Produção de texto & $\begin{array}{l}\text { A Crônica (I) } \\
\text { Agora é a sua vez }\end{array}$ \\
\hline A língua em foco & O predicativo do objeto e o predicado verbo-nominal \\
\hline Divirta-se & Jogo de memória \\
\hline
\end{tabular}


Para este trabalho, focamos as seções intituladas "Estudo do texto" e suas subseções "Compreensão e interpretação" e "A linguagem do texto"; e a seção "Produção de texto". O Estudo do Texto aborda atividades de compreensão e interpretação da crônica "Porta de colégio", de Affonso Romano de Sant'Ana. Embora tenham questões que contemplem etapas cognitivas do processo de leitura e proporcionem o trabalho com o nível inferencial, há também atividades que ainda remetem apenas à decodificação e à transcrição do texto. Elas seguem a ordem linear da crônica, concentrandose no objetivo de levar o aluno a identificar as principais ideias da crônica. É o que confirmam alguns exemplos:

\footnotetext{
- Ainda no 1ำ parágrafo, o narrador percebe que a sensação que teve pode ser alvo da crítica de seu leitor.

a) Que frase evidencia essa consciência?

b) Por que a sensação que o narrador teve poderia ser qualificada dessa forma?

- Situados entre a infância e a vida, alguns adolescentes que começam a entrar pela "porta da vida" já sofrem os primeiros impactos da vida.

a) Que palavras ou expressões empregadas no $2^{\circ}$ parágrafo, de sentidos opostos entre si, mostram a fase de transição vivida pelos adolescentes?

b) Que exemplo de impacto é mencionado no texto, no $2^{\circ}$ parágrafo?
}

Cereja e Magalhães, p.158, 2012.

Observamos que, na prática de leitura, os autores não abordam noções acerca do contexto de produção do gênero crônica, como o local de circulação, o suporte de publicação que levariam o aluno a refletir e inferir sobre os implícitos no texto, estabelecendo uma relação com a sua temática. Entendemos que os autores também poderiam ter trabalhado, por exemplo, o papel social do cronista e do leitor e suas intenções, além de apresentar os dados biográficos e literários do autor, a fim de colaborar nas etapas de compreensão e interpretação do texto.

Como forma de complementar a prática de leitura, sugerimos alguns pontos específicos que poderiam fazer parte de um momento de leituraanalítica do funcionamento discursivo do gênero crônica, levando o aluno a perceber que: a) o papel social assumido pelos cronistas é o de fazer o leitor refletir sobre questões simples da vida, que nos passam despercebidas, via 
leitura de entretenimento; b) o papel social do leitor, revelado discursivamente, é aquele que deseja refletir sobre a própria vida, via diversão; c) o público específico das crônicas é determinado pelo enunciado, não só em relação a sua maior ou menor complexidade, mas também, pelas temáticas variadas das quais tratam e que demandam tal diversidade de conhecimentos; d) o tom irônico e despretensioso dos autores funciona como o lugar do estabelecimento e da ancoragem da entonação do gênero (um tom autorizado) e da sua atitude valorativa.

Sob este aspecto, parece-nos que, para o trabalho com a leitura, os autores não levam em conta as condições de produção do texto-enunciado lido, que, no caso, é um exemplar do gênero crônica. Essa atitude nos parece contraditória, uma vez que uma das implicações pedagógicas essenciais dos pressupostos da teoria bakhtiniana à prática de leitura, na concepção de linguagem como interação social entre os sujeitos, é o aspecto dialógico como dimensão constitutiva da linguagem (BAKHTIN; VOLOCHINOV, 1988; BAKHTIN, 2003). No que tange à compreensão das bases teóricas do Círculo, é muito importante a premissa das relações dialógicas como relações de sentido entre os enunciados, sendo o sentido inscrito em vozes discursivas.

Já, na subseção $A$ Linguagem do Texto há um número menor de exercícios e os autores trabalham determinados recursos linguísticos como o uso de substantivos, pronomes e advérbios, sem a preocupação com classificações, mas como elementos que participam na construção dos sentidos do texto. Como podemos observar nos exemplos:

\footnotetext{
- Releia este trecho do texto: "Pudesse Ihes diria daqui: aproveitem enquanto estão no aquário e na redoma, enquanto estão na porta da vida e do colégio. $O$ destino também passa por aí".

Os termos daqui e aí indicam a posição do narrador em relação aos jovens que ele observa.

a) A que lugar corresponde o termo daqui?

b) E o termo aí?
}

Cereja e Magalhães, p.158, 2012

No entanto, tais atividades não exploram a complexidade linguísticoenunciativa que envolve o gênero discursivo crônica. Consideramos que a crônica lida ofereceria boas possibilidades de trabalho, por exemplo, com a 
linguagem conotativa e com o uso do discurso indireto, mas a utilização desses recursos linguístico-enunciativos e seus efeitos de sentido não foram explorados. Há, portanto, uma lacuna no processo de recepção de textos, visto que o trabalho instrumentalizador da prática de análise linguística no momento da leitura não se concretizou.

Acreditamos que é por meio da seleção do gênero discursivo e, consequentemente, da seleção da estrutura composicional, do léxico, das escolhas morfossintáticas, enfim, dos recursos linguístico-enunciativos veiculados que se produzem ou coproduzem efeitos de sentido. Pelas escolhas linguísticas do locutor-autor podemos visualizar tanto os aspectos da situação enunciativa quanto, também, aspectos da subjetividade desse locutor-autor, que se revela e se mostra como sujeito. Dessa forma, validamos o que defendem Geraldi (1997), Perfeito (2006), entre outros autores, acerca da não dicotomia entre as práticas de leitura e análise linguística, na medida em que esta última só tem sentido de ser no interior das outras práticas - leitura e produção de textos - formando o tripé do trabalho docente com Língua Portuguesa.

A fim de contribuirmos com a proposta do livro didático, pontuamos as seguintes marcas linguístico-enunciativas que podem caracterizar o estilo da crônica e serviriam como foco de questões de análise linguística: a) uso da estratégia discursiva da ironia e, como consequência, mobilização de implícitos referenciais para a compreensão do tom irônico; b) para engajar o leitor: verbo e pronome na $1^{\text {a }}$ pessoa do plural, perguntas retóricas, presença de operadores modais, como pronome indefinido "todos" e de advérbios ou expressões adverbiais com sentido de inclusão; c) expressões modalizadoras "sim", "claro" - como estratégia de antecipar a possível contrapalavra do leitor; d) emprego do nível informal de linguagem, com o objetivo de garantir ao leitor uma leitura mais leve, por meio de gírias, variante coloquial, presença de marcas da oralidade (RITTER, 2012).

Na próxima seção do capítulo intitulado Produção de texto, os autores apresentam o gênero "Crônica", apontam uma breve definição do gênero e fazem perguntas acerca das características do texto lido, explorando os personagens, o narrador, o espaço, o tempo, já que a crônica lida foi caracterizada como crônica narrativa. Consideramos louvável o fato de os 
autores não trazerem uma definição pronta do gênero, uma vez que levam os alunos à elaboração de algumas de suas características por uma metodologia indutiva. Porém, podemos afirmar que o foco das questões priorizou somente aspectos voltados à estrutura composicional. Chega-se a indagar acerca da variedade linguística utilizada, um dos componentes do estilo do gênero, mas não se articula essa reflexão com elementos da situação de produção que a determinou.

Além disso, observamos que a definição apresentada do gênero não alertou os alunos sobre o fato de que a estrutura da crônica não segue um padrão fixo, podendo-se empregar tanto a estrutura narrativa como outras que não sejam narrativas. Portanto, ao nosso ver, seria mais produtivo para a aprendizagem do aluno exemplificar uma outra forma composicional da crônica, que pode ser denominada de comentário.

Podemos considerar como crônica comentário a que se organiza em uma estrutura não-narrativa e que pode apresentar as seguintes categorias estruturais:

a) parte-se de uma observação de caráter mais pessoal ou ainda de uma experiência vivida ou pelo próprio cronista ou de algum conhecido para contextualizar o tema abordado;

b) apresentam-se sequências textuais de relato, de opinião, de expressão de sentimentos para o desenvolvimento das reflexões do cronista sobre o tema;

c) conclui-se para retomar as reflexões, podendo finalizar com frases ou períodos de efeito humorístico, sarcástico ou ainda irônico (RITTER, 2012, p. 196).

Após a caracterização do gênero, Cereja e Magalhães (2012), no tópico "Agora é a sua vez", trazem uma proposta de produção de texto. Sugerem que o aluno se lembre de uma situação cotidiana vivida ou observada na mídia e escreva uma crônica sobre ela. Apresentam as seguintes instruções para a produção:

a) Pensar no leitor, pois a crônica será publicada num livro de crônicas da classe e lida por colegas, professores, funcionários, pais, amigos e convidados para a mostra O ADOLESCENTE: NÃO AO NÃO, apresentada no projeto do capítulo 


\section{INTERVALO da unidade.}

b) Abordar o fato narrando com sensibilidade ou com humor, lembrando-se de mencionar o lugar onde aconteceu o fato, o tempo, a caracterização das personagens. Utilizar o discurso direto se quiser dar mais dinamismo à narrativa. Escrever de forma simples empregando a variedade-padrão informal.

c) Fazer um rascunho e só passar o texto a limpo no livro de crônicas, após cuidadosa revisão, seguindo as orientações do boxe Avalie sua crônica.

Cereja e Magalhães, p.160, 2012.

Quanto à proposta de escrita textual, avaliamos que os autores do LD elaboraram uma proposta que, se de um lado, articula-se com a temática do projeto Intervalo que deverá concluir a unidade, de outro, faltam parâmetros anteriores de estudo da própria crônica para auxiliar o aluno na escrita. De fato, destacam o papel importante do interlocutor do texto, pois sugerem que as crônicas sejam publicadas num livro da turma e sejam lidas pela comunidade escolar. Porém, dado o fato que a seção de leitura apenas contemplou aspectos da organização composicional e que não servem para todas as crônicas, tendo em visto a instabilidade desse gênero, falta ao aluno subsídios para a sua produção. Muito provavelmente, o aluno produzirá uma narrativa escolar, pois, na prática da leitura, não se trabalharam as marcas estilísticas desse gênero. Além disso, entendemos que esse gênero, pela própria plasticidade, não é adequado para a proposta de produção textual, mas para a prática de leitura. Ou seja, o comando de produção atende muito parcialmente às condições de produção do gênero, mascara, na realidade, uma preocupação muito mais voltada à língua morta e à tipologia narrativa que ao enunciado concreto.

Solicitar uma produção de texto, nesse momento em que apenas uma crônica foi analisada pode ser prematuro, pois os alunos tiveram pouco contato com o gênero. Talvez fosse mais oportuno que os alunos fossem expostos a leituras de outras crônicas, que pudessem pesquisar mais crônicas na biblioteca da escola ou pela internet e depois levassem para a sala de aula. Conforme nosso entendimento, após a realização de leituras diversificadas, os alunos poderiam estar preparados mais adequadamente para a primeira produção. Segundo Antunes (2003, p.45), a partir de uma visão interacionista de escrita "[...] se supõe que alguém selecionou alguma coisa a ser dita a outro 
alguém, com quem pretendeu interagir, em vista de algum objetivo". Logo, o aluno precisa ser instrumentalizado sobre o gênero em questão para que de fato cumpra com estas orientações satisfatoriamente.

Além disso, as orientações dadas aos alunos para realizarem a revisão da escrita de seus textos são muito amplas, pouco específicas. Por isso, apresentamos uma sugestão de critérios que poderiam auxiliar na autoavaliação:

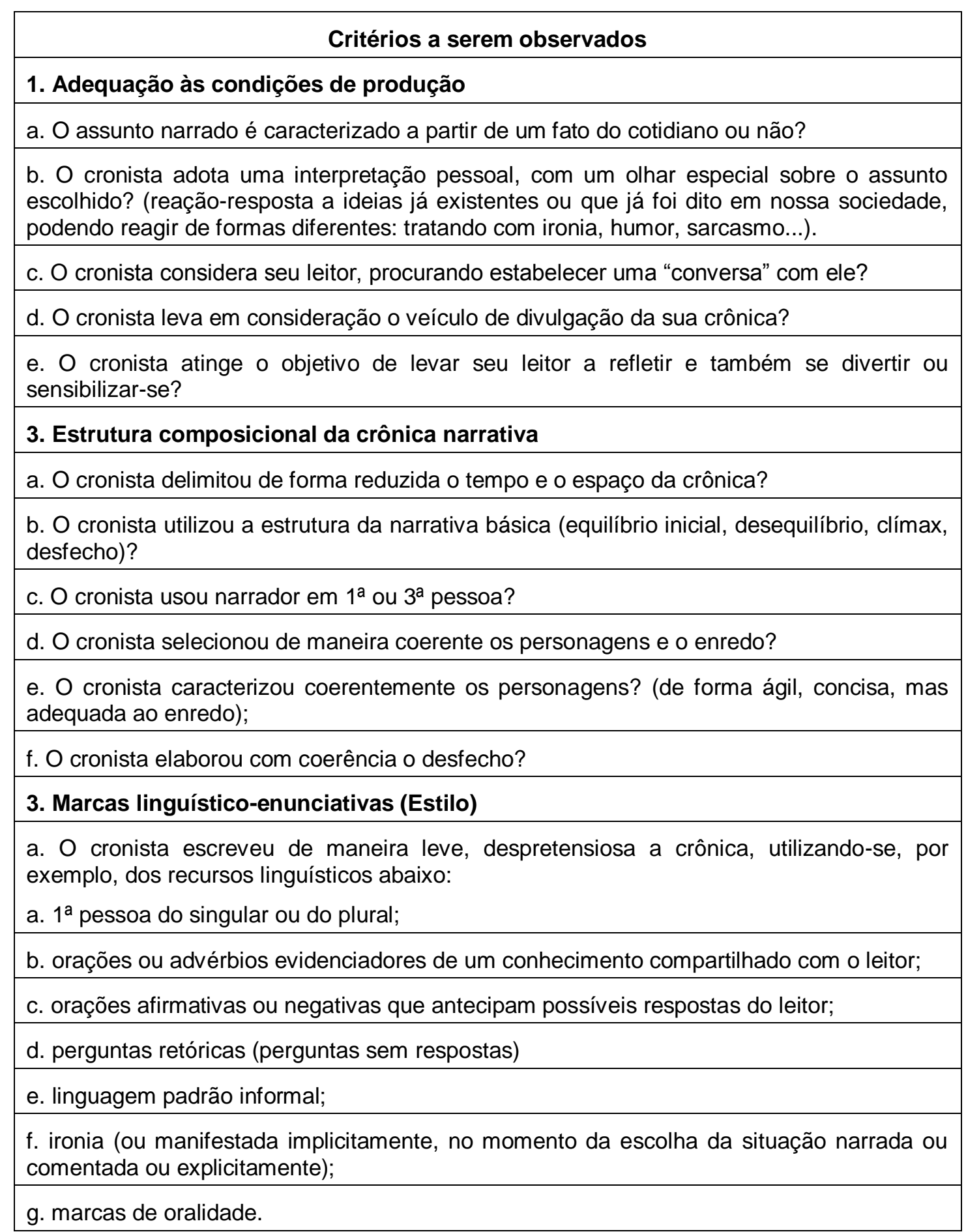




\section{Considerações finais}

Consideramos que no LD analisado neste estudo, os autores Cereja e Magalhães (2012) apresentam propostas lacunares no que diz respeito à análise enunciativa tanto para a prática da leitura como para a prática da produção textual. Muitos dos exercícios de leitura sugeridos ainda mesclam atividades descontextualizadas, principalmente no que tange ao estudo da gramática, ainda trabalhada conforme os preceitos tradicionais de língua. Também na produção textual, muito embora o comando privilegie 0 interlocutor, todo o trabalho se volta mais para a preocupação com elementos da tipologia narrativa. Além disso, devido à ausência do trabalho com as marcas estilísticas da crônica, o aluno não tem parâmetros para diferenciar este gênero da narração escolar. E, apesar de o Manual do Professor demonstrar uma preocupação com o enunciado concreto, o capítulo revela-se bastante superficial e descontextualizado em relação ao gênero crônica.

\section{Referências:}

ANTUNES, I. Aula de português: encontro \& interação. São Paulo: Parábola Editorial, 2003.

BAKHTIN, M. Os gêneros do discurso. In: Estética da criação verbal. São Paulo: Martins Fontes, 1997.

BAKHTIN. M. Estética da criação verbal. Trad. De Paulo Bezerra. São Paulo: Martins Fontes, 2003.

BRASIL. Parâmetros Curriculares Nacionais. Linguagens, códigos e suas tecnologias. Brasília: Ministério da Educação/Secretaria de Educação Média e Tecnológica, 1998.

CEREJA, W. R.; MAGALHÃES, T. C. Português Linguagens, $8^{\circ}$ ano. 7. ed. reform. São Paulo: Saraiva 2012.

COSTA-HÜBES, T. da C. Os gêneros discursivos como instrumentos para o ensino de Língua Portuguesa: perscrutando o método sociológico Bakhtiniano como ancoragem para um encaminhamento didático-pedagógico. In: NASCIMENTO, E. L.; ROJO, R. H. R. (Orgs.). Gêneros de texto/discurso e os desafios da contemporaneidade. Campinas, 2014. 
GERALDI, J. W. Portos de passagem. 4. ed. São Paulo: Martins Fontes, 1997.

PARANÁ. Secretaria de Estado da Educação. Diretrizes Curriculares da disciplina de Língua Portuguesa do Estado do Paraná. Curitiba, 2008.

PERFEITO, A. M. Análise linguística e construção de sentidos. In: LIMOLI, L.; MENDONÇA, A. P. F. Nas fronteiras da linguagem: leitura e produção de sentidos. Londrina: Editorial Mídia, 2006. p. 7-16.

RITTER, L. C. B. Práticas de leitura/análise linguística com crônicas no Ensino Médio: proposta de elaboração didática. 2012. 240 f. Tese (Doutorado em Estudos da Linguagem)-Universidade Estadual de Londrina, Londrina, 2012.

RODRIGUES, R. H. A pesquisa com os gêneros do discurso na sala de aula: resultados iniciais. In: CELLI - COLÓQUIO DE ESTUDOS LINGUÍSTICOS E LITERÁRIOS. 3, 2007, Maringá, Anais...Maringá, 2009, p.2010-2019.

SCHNEUWLY, B., DOLZ, J. Gêneros orais e escritos na escola. Tradução de Roxane Rojo e Glaís Sales Cordeiro. Campinas: Mercado de Letras, 2004. 
Artigo recebido em: 31 de agosto de 2015

Artigo aprovado em: 15 de junho de 2016

\section{Sobre as autoras:}

Lilian Cristina Buzato Ritter concluiu doutoramento em 2012, no programa de pós-graduação em Estudos da Linguagem, pela Universidade Estadual de Londrina (UEL). Possui Mestrado em Linguística Aplicada pela Universidade Estadual de Maringá (1999). A partir de 2013, atua como professora efetiva no Programa de Mestrado Profissionalizante em Letras (PROFLETRAS-UEM).

Claudia Valéria Doná Hila possui graduação em Letras pela Universidade Estadual de Maringá (1984), mestrado em Letras pela Universidade Estadual de Maringá (1999) e doutorado em Estudos da Linguagem pela Universidade Estadual de Londrina (2011). 